\title{
NONALCOHOLIC STEATOHEPATITIS CHALLENGES HEPATITIS B VIRUS AS THE LEADING CAUSE OF CHRONIC HEPATITIS IN BANGLADESH
}

\author{
MAMUN-AL- MAHTAB ${ }^{1}$, DULAL CHANDRA DAS ${ }^{2}$, MOHAMMAD ABDUR RAHIM ${ }^{3}$, ROKSHANA BEGUM ${ }^{4}$, \\ SHEIKH MOHAMMAD NOOR-E-ALAM ${ }^{5}$, AHMED LUTFUL MOBEN ${ }^{6}$, AYUB AL MAMUN ${ }^{7}$, SALIMUR RAHMAN $^{8}$, \\ SHEIKH MOHAMMAD FAZLE AKBAR ${ }^{9}$
}

\begin{abstract}
Background: Chronic hepatitis is inflammation of the liver that lasts at least 6 months. Knowledge of aetiology and pattern of development of complications of chronic liver disease will help in designing optimal and cost effective control measures of the disease. Methods: The present study was performed to find out the aetiological factors in patients of chronic liver disease. This was a retrospective, cross-sectional study. Patients attending Hepatology Green Unit, Bangabandhu Sheikh Mujib Medical University, Dhaka in 2014 with chronic hepatitis were included. Results: Total 3250 patients were studied, 2310(71.08\%) males and 940(28.92\%) females. Most of the patients 1547 (47.6\%) belong to age group of 18 to 30 years followed by 922 (28.37\%) who were between the age group of 31-40 years. Majority of patients 2012(61.91\%) had HBV infection, 1095(33.69\%) had nonalcoholic steatohepatitis (NASH), 81(2.49\%) had HCV infection, 7(0.22\%) had alcohol abuse, 28(0.86\%) had Wilson's disease, $19(0.58 \%)$ had autoimmune hepatitis and no aetiological factors were recorded in $8(0.25 \%)$ patients. However in case of females $52.55 \%$ (494/940) due to NASH, while $40.21 \%$ (378/940) due to HBV. Conclusion: HBV infection is the major risk factor for chronic liver disease and NASH challenges $H B V$ in our patients.
\end{abstract}

Key Words: Chronic hepatitis B, Chronic hepatitis $C$ infection, nonalcoholic steatoheapatitis, alcohol.

\section{Introduction}

Chronic hepatitis is inflammation of the liver that lasts at least 6 months. Common causes include hepatitis B and C viruses and certain drugs. Many people have no symptoms, but some have vague symptoms, such as a general feeling of illness, poor appetite and fatigue. Chronic hepatitis can result in cirrhosis, with an enlarged spleen, accumulation of fluid within the abdomen, and deterioration of brain function. A biopsy is done to confirm the diagnosis. Chronicity of liver disease is determined either by duration of liver disease (typically $>6$ months) or by evidence of either severe liver disease or physical stigmata of chronic liver disease (clubbing, spider telangiectasia and hepatosplenomegaly). The severity is variable; the affected patient may have only biochemical evidence of liver dysfunction, may have stigmata of chronic liver disease, or may present in hepatic failure. Chronic liver disease may be caused commonly by persistent viral infections (chronis HBV or HCV infection), metabolic diseases, drugs, autoimmune hepatitis or unknown factors. ${ }^{1}$ Examining the trend of the disease over a time period becomes an important tool to observe the variation of its different aspect and provide the status of country's public health system..$^{2-3}$

1. Department of Hepatology, Bangabandhu Sheikh Mujib Medical University, Dhaka

2. Department of Hepatology, Bangabandhu Sheikh Mujib Medical University, Dhaka

3. Department of Hepatology, Abdul Malek Ukil Medical College, Noakhali

4. Department of Hepatology, Bangabandhu Sheikh Mujib Medical University, Dhaka

5. Department of Hepatology, Bangabandhu Sheikh Mujib Medical University, Dhaka

6. Kurmitola General Hospital, Dhaka

7. Department of Hepatology, Bangabandhu Sheikh Mujib Medical University, Dhaka

8. Department of Hepatology, Bangabandhu Sheikh Mujib Medical University, Dhaka

9. Department of Medical Sciences, Toshiba General Hospital, Tokyo.

Bangladesh J Medicine 2017; 28 : 24-27 


\section{Methods}

This is a cross-sectional descriptive study. This is a retrospective study. Patients attending Hepatology Green Unit, Bangabandhu Sheikh Mujib Medical University, Dhaka, from January 2014 to December 2014 with chronic liver disease were included. Data was retrieved from the out patient and in patient registry of the unit. Patients having evidence of chronic liver disease on clinical, biochemical , liver biopsy, ultrasound examination of abdomen and fibroscan of liver were included in this study. The diagnosis of NASH was based on biochemistry i.e. elevated serum alanineaminotransferase (ALT) and ultrasonography of hepato-biliary system. Some of the patients also underwent fibroscan of live and/or percuteneous liver biopsies when the diagnosis could not be established based on biochemistry and ultrasonography. All patients were carefully examined to determine the etiology of NASH.

\section{Results}

During the study period, 3250 patients with a diagnosis of chronic hepatitis were studied. Since the Department of Hepatology at Bangabandhu Sheikh Mujib Medical University is not only the pioneering, but to date also the only fully organized hepatology department of the country, it has to cater the need of patients suffering from liver diseases from all over the country. Among the study population, majority were 2310 (71.08\%) males and 940 (28.92\%) were females. In present study, most of the patients 1547 $(47.6 \%)$ belong to age group of 18 to 30 years followed by $922(28.37 \%)$ who were between the age group of 31-40 years. This study showed that HBV infection was the major aetiological factor and responsible for $61.91 \%$ of the total cases. We also observed $33.69 \%$ of patients with chronic hepatitis due to nonalcoholic steatohepatitis (NASH) and $\mathrm{HCV}$ in $2.49 \%$ chronic hepatitis. Chronic hepatitis due to alcohol abuse in $0.22 \%$, autoimmune hepatitis in $0.58 \%$. In this study, $0.86 \%$ chronic hepatitis patient had Wilson's disease and etiological factor was not recognized in $0.25 \%$ of patients. However in case of females $52.55 \%$ (494/ 940) due to NASH, while $40.21 \%$ (378/940) due to HBV (Table-I, II).

HBV infection was responsible for $61.91 \%$ of the total cases and $33.69 \%$ of patients due to nonalcoholic steatohepatitis (NASH) and $\mathrm{HCV}$ in $2.49 \%$ patients. Chronic hepatitis due to alcohol abuse in $0.22 \%$, autoimmune hepatitis in $0.58 \%$, Wilson's disease in $0.86 \%$ and aetiological factor was not recognized in $0.25 \%$ of patients. In case of females $52.55 \%$ (494/ 940) due to NASH, while $40.21 \%(378 / 940)$ due to HBV (Table-III).

Table-I

Age distribution of Male Patients

\begin{tabular}{|c|c|c|c|c|c|}
\hline Male & $18-30$ Yrs & $31-40$ Yrs & 41-50 Yrs & 51-60 Yrs & Above 60 Yrs \\
\hline HBV Infection & 1057 & 405 & 120 & 37 & 15 \\
\hline NASH & 135 & 206 & 146 & 92 & 22 \\
\hline Infection & 16 & 11 & 9 & 2 & 6 \\
\hline Alcohol & - & - & 4 & 3 & - \\
\hline Wilson"s Disease & 5 & 4 & 4 & - & - \\
\hline Autoimmune Hepatitis & 1 & 2 & 3 & 2 & - \\
\hline Unknown & - & - & 2 & 1 & - \\
\hline
\end{tabular}

Table-II

Age distribution of female patients:

\begin{tabular}{lccccc}
\hline Female & $18-30$ Yrs & $31-40$ Yrs & $41-50$ Yrs & 51-60Yrs & Above 60 Yrs \\
\hline HBV Infection & 225 & 83 & 45 & 17 & 8 \\
NASH & 92 & 187 & 139 & 54 & 7 \\
HCV Infection & 5 & 16 & 5 & - & - \\
Alcohol & - & - & 3 & 2 & - \\
Wilson"s Disease & 9 & 3 & 4 & - & - \\
Autoimmune Hepatitis & 2 & 3 & 3 & - \\
Unknown & - & 2 & & & - \\
\hline
\end{tabular}


Table-III

Aetiological factors of chronic hepatitis.

\begin{tabular}{lcccccc}
\hline Factors & \multicolumn{2}{c}{ Male } & \multicolumn{2}{c}{ Female } & \multicolumn{2}{c}{ Positive proportion } \\
& No & $\%$ & No & $\%$ & No & $\%$ \\
\hline HBV Infection & 1634 & 81.21 & 378 & 18.79 & 2012 & 61.91 \\
NASH & 601 & 54.89 & 494 & 45.11 & 1095 & 33.69 \\
HCV Infection & 44 & 54.32 & 37 & 45.68 & 81 & 2.49 \\
Alcohol & 7 & 100.00 & - & 00.00 & 7 & 0.22 \\
Wilsons Disease & 13 & 46.43 & 15 & 53.57 & 28 & 0.86 \\
Autoimmune Hepatitis & 8 & 42.11 & 11 & 57.89 & 19 & 0.58 \\
Unknown Cause & 3 & 37.50 & 5 & 62.50 & 8 & 0.25 \\
\hline
\end{tabular}

\section{Discussion}

This is the second study on aetiological factors of chronic hepatitis from Bangladesh. Unlike the West (where alcohol and HCV are the principle causes of chronic liver disease), HBV still the leading cause of chronic liver disease related morbidity and mortality.

This study, a hospital based study where most of the patient were from low socioeconomic status. Male predominance $(71.08 \%)$ was observed in present study and most of the patients (90.95\%) were of age group 18-50 years, which is similar to the study done by $\mathrm{Pal}$ et al at Kolkata where $79 \%$ of patients were male and $54 \%$ of patients belonged to age group 31 to 50 years indicating that chronic liver disease is more common in male suggesting high risk of exposure to causative factors. ${ }^{4}$

This study showed that HBV infection was the major aetiological factor and responsible for $61.91 \%$ of the total cases. We also observed $33.69 \%$ of patients with chronic hepatitis due to nonalcoholic steatohepatitis (NASH) and HCV in $2.49 \%$ patients. Chronic hepatitis due to alcohol abuse in $0.22 \%$, autoimmune hepatitis in $0.58 \%$. In this study, $0.86 \%$ chronic hepatitis patient had Wilson's disease and aetiological factor was not recognized in $0.25 \%$ of patients. However in case of females $52.55 \%$ (494/940) due to NASH, while $40.21 \%(378 / 940)$ due to HBV.

The aetiology of chronic liver disease was an arena where much difference was noted in our study from those of Western Countries. In a large multicenter study done by Stroffoline et al searching for the etiology of chronic hepatitis in Italy studied 6210 patients consecutively admitted to 79 hospitals throughout Italy. They found chronic hepatitis C $(62.6 \%)$ as most common etiological factor, chronic hepatitis B in $9.2 \%$ and history of alcohol abuse was present in $19.2 \%$ of cases, but only $5.2 \%$ cases were without viral infection and had only alcohol abuse ${ }^{5}$ Velosa et al from Portugal in a study of 988 patients of chronic liver disease found viral aetiology in $82 \%$, metabolic in $2 \%$, biliary in $2 \%$, alcoholic in $11 \%$, autoimmune in $1.5 \%$, and idiopathic in $2 \%$. Among viral group, hepatitis B virus infection in $65 \%$, hepatitis $\mathrm{C}$ in $26 \%$ and hepatitis D was found in $8 \%{ }^{6}$ Almost similar aetiological profile was seen in present study. Khokhar from Islamabad in a study of 518 patients of chronic liver disease, biopsy proven chronic hepatitis was present in 354 patients. Out of these $86 \%$ had hepatitis $\mathrm{C}, 10.7 \%$ hepatitis $\mathrm{B}, 3.1 \%$ had both B and C.7 A study of 44 patients by Acharya et al at AIIMS, New Delhi found 50\% of patients had chronic Hepatitis B, associated hepatitis D with hepatitis B in $21 \%$, hepatitis C in $15 \%$, non-A, non-B other than Hepatitis $C$ virus in $13 \%, 2 \%$ patients had autoimmune hepatitis.$^{8}$

At least 5-10\% of infected patients, develop chronic liver disease and cirrhosis develops in about 10-20\% patients within 5-20 years. NASH is more likely to occur with people who are obese, diabetes patients, those with high blood lipid levels, as well as individuals with hypertension. $\mathrm{NASH}$, in its early stages, begins with the accumulation of too much fat in the liver. The fat causes inflammation and scarring and fibrosis resulting in possible cirrhosis later on. Present study definitely observed NASH related chronic liver disease in the coming years and may act as an early guide for government policy in this direction.

Although overall HBV remains the leading cause of chronic hepatitis in Bangladesh (76.3\% in 2007), NASH (22.8 \% in 2007) is increasingly becoming important as the leading etiology of chronic hepatitis in this country, especially in case of females. 


\section{Conclusion}

Chronic liver disease is a common entity in Bangladesh with male preponderance and affecting mostly people of young and middle age group. HBV is the commonest cause of chronic hepatitis in Bangladesh. The government has integrated HBV vaccine into the existing Expanded Programme on Immunization. A multidisciplinary approach for prevention and control of HBV infection must be adopted to make the public awareness through the mass media about its complications and possible modes of transmission. Moreover with our economic growth, lifestyle-related disease like fatty liver is becoming an important concern.

\section{References}

1. Benjamin L, Frederick J. Autoimmune and chronic hepatitis. In:Kliegman R, Behrman R, Jensen H, Santon B, (editors). Nelson Text Book of Paediatrics. Philadelphia:Saunders; 2007. p.1698.
2. Vong S, Bell BP. Chronic liver disease mortality in the United States, 1990-1998. Hepatology. 2004;39:476-83.

3. Ray G. Trends of chronic liver disease in a tertiary care referral hospital in Eastern India. Indian $\mathrm{J}$ Public Health. 2014;58:186-94.

4. Pal J, Dasgupta S, AgarwalV, Kejariwal D, Roy S, Majumder AK. Clinical profile of chronic liver diseases in a tertiary care center in Kolkata. Japi. 2003; 51: 1173-4.

5. Stroffolini T, Sagnelli E, Mele A, Craxì A, Almasio P. The aetiology of chronic hepatitis in Italy: results from a multicentre national study. Dig Liver Dis. 2004;36:829-33.

6. Velosa J, Ramalho F, Serejo F, Marinho R, de Moura MC. Chronic hepatitis: The etiological spectrum, The implications for treatment. Acta Med Port. 1993;6:233-8.

7. Khokhar N. Spectrum of chronic liver disease in a tertiary care hospital. J Pak Med Assoc. 2002;52:56-8.

8. Acharya SK, Panda SK, Duphare H, Dasarathy S, Ramesh R, Janeel $\mathrm{S}$ et al. Chronic hepatitis in a large Indian Hospital, AIIMS, New Delhi. Natl Med J India. 1993;6:202-6. 